\title{
Efficacy of aflibercept for the treatment of chronic non-ischemic CRVO-associated macular edema after treatment with other anti- VEGF agents
}

\author{
Bozho Todorich ${ }^{1,2^{*}}$, Phoebe Lin ${ }^{1,2}$, Christine Shieh ${ }^{1,2}$ and Sharon Fekrat ${ }^{1,2}$ \\ *Correspondence: btodorich@gmail.com CrossMark \\ 'Duke University Eye Center, Erwin Road, PO Box 3802, Durham, NC 27710, USA. \\ ${ }^{2}$ Durham Veterans Affairs Medical Center, 508 Fulton Street, Durham, NC 27705, USA.
}

\begin{abstract}
Objective: To describe a patient with a perfused CRVO that responded to intravitreal aflibercept after prior treatment with intravitreal bevacizumab and intravitreal ranibizumab.

Design: Retrospective report of a case.

Methods: Institutional retrospective review of a single case of a patient with CRVO-related macular edema treated with anti-VEGF agents (bevacizumab, ranibizumab and aflibercept). Baseline demographics, visual acuity and OCT scans are reported.

Results: A 62 year old male with a perfused CRVO with marked cystoid macular edema was treated with intravitreal aflibercept and subsequently experienced significant improvement in visual acuity and central foveal thickness. This effect was observed despite prior treatment with intravitreal bevacizumab as well as intravitreal ranibizumab.

Conclusion: Intravitreal aflibercept is a viable treatment option for macular edema due to CRVO in eyes even after prior treatment with other anti-VEGF agents.

Keywords: CRVO, bevacizumab, ranibizumab, aflibercept, VEGF, macular edema
\end{abstract}

\section{Introduction}

Retinal vein occlusion is a significant cause of visual loss, involving $1 \%$ of Americans age 40 and older and affecting 2.5 million people worldwide $[\mathbf{1}, 2]$. Central retinal vein occlusion (CRVO) purportedly arises from thrombosis of the vein at the level of the lamina cribrosa [3]. This results in retinal venous congestion producing a constellation of findings including intraretinal edema, disc edema, intraretinal hemorrhages and/or cotton wool spots in all four quadrants of the retina $[4,5]$. Although CRVO may also produce vision loss through macular ischemia, vitreous hemorrhage or neovascular glaucoma, macular edema represents a major cause of visual loss associated with CRVO [4]. Cystoid macular edema (CME) in CRVO occurs because of leakage of fluid from the retinal perifoveal microvasculature [5]. Furthermore, vascular endothelial growth factor (VEGF) has been identified as a major contributor to the development of CME in CRVO, driving microcapillary permeability through downregulation of capillary tight junctions $[6,7]$. For several years, the anti-VEGF agents, ranibizumab (Lucentis, Genentech) and bevacizumab (Avastin, Genentech), have been used with success to treat macular edema in eyes with CRVO. A randomized, sham-controlled clinical trial CRUISE (Ranibizumab for the Treatment of Macular Edema After Central Retinal Vein Occlusion Study: Evaluation of Efficacy and
Safety) established efficacy of intravitreal ranibizumab for CME in CRVO patients [7]. A smaller, non-randomized prospective study similarly showed the efficacy of bevacizumab for CRVOrelated macular edema with improvement in visual acuity and central foveal thickness (CFT) [8]. VEGF Trap-Eye, now known as aflibercept (Eylea, Regeneron Pharmaceuticals), is being assessed in a phase III sham-controlled study (COPERNICUS) for its use in CME related to de novo CRVO, not previously treated with other anti-VEGF agents or laser [9]. The 6-month study results demonstrated better visual and anatomic outcomes in aflibercept-injected eyes compared to sham controls. To our knowledge, there are no published or ongoing studies looking at the efficacy of aflibercept after prior anti-VEGF therapy in CRVO. We report a patient with a chronic non-ischemic CRVO previously treated with intravitreal bevacizumab and ranibizumab who had significant improvement in visual acuity and CFT after receiving a single intravitreal injection of aflibercept. The clinical response demonstrates the benefits of aflibercept for the treatment of chronic CRVO even after treatment with other anti-VEGF agents.

\section{Case presentation}

A 62 year old hypertensive male developed a non-ischemic CRVO with associated CME in his right eye. At the time of initial 
Todorich et al. Journal of Eye and Ophthalmology 2014,

http://www.hoajonline.com/journals/pdf/2055-2408-1-3.pdf

diagnosis, the patient received a total of ten intravitreal injections of bevacizumab over a period of two and a half years at an outside ophthalmology clinic. The injections occurred at 2-3 month intervals with subsequent improvement in best corrected visual acuity (BCVA) and macular edema. Outside records revealed a visual acuity of 20/160 just prior to his last bevacizumab injection and a CFT of $738 \mu \mathrm{m}$ (Figure 1A). Ten weeks after treatment with $1.25 \mathrm{mg}$ of intravitreal bevacizumab, there was improvement in CFT to $319 \mu \mathrm{m}$ on OCT and visual acuity to 20/70 (Figure 1B).
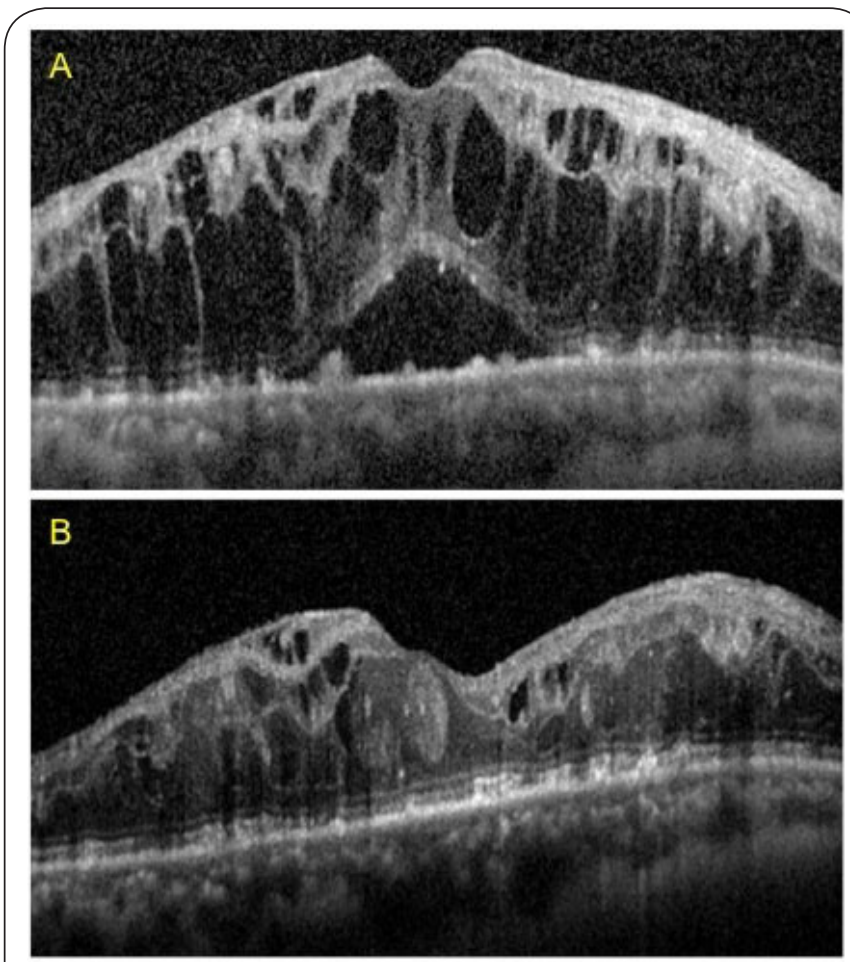

Figure 1. Macular SD-OCT images (Spectralis) before and after intravitreal bevacizumab. (A) Significant CME with subretinal subfoveal fluid, BCVA 20/160, CFT of $738 \mu \mathrm{m} / 12.99 \mathrm{~mm}^{2}$ prior to treatment. (B) Reduced CME with resolution of subretinal fluid, BCVA 20/70, CFT of $319 \mu \mathrm{m} / 9.27 \mathrm{~mm}^{2} 10$ weeks after bevacizumab injection.

The patient presented to our clinic approximately two and a half years after diagnosis with CRVO and approximately seven months after his last bevacizumab injection. At that time, he had persistent CME and a visual acuity of 20/70. He received intravitreal ranibizumab, but was lost to follow up for four months. Upon return he had decreased visual acuity to 20/400 and increased macular edema (CFT of $821 \mu \mathrm{m}$ ) (Figure 2A). He received an injection of intravitreal ranibizumab which resulted in significant improvement in CFT to $357 \mu \mathrm{m}$ on OCT (Figure 2B) and improved visual acuity to 20/80 six weeks later. Despite continued ranibizumab injections, visual acuity did not improve further and CME did not fully resolve even at 4 weeks. Compliance with follow-up visits was inconsistent.
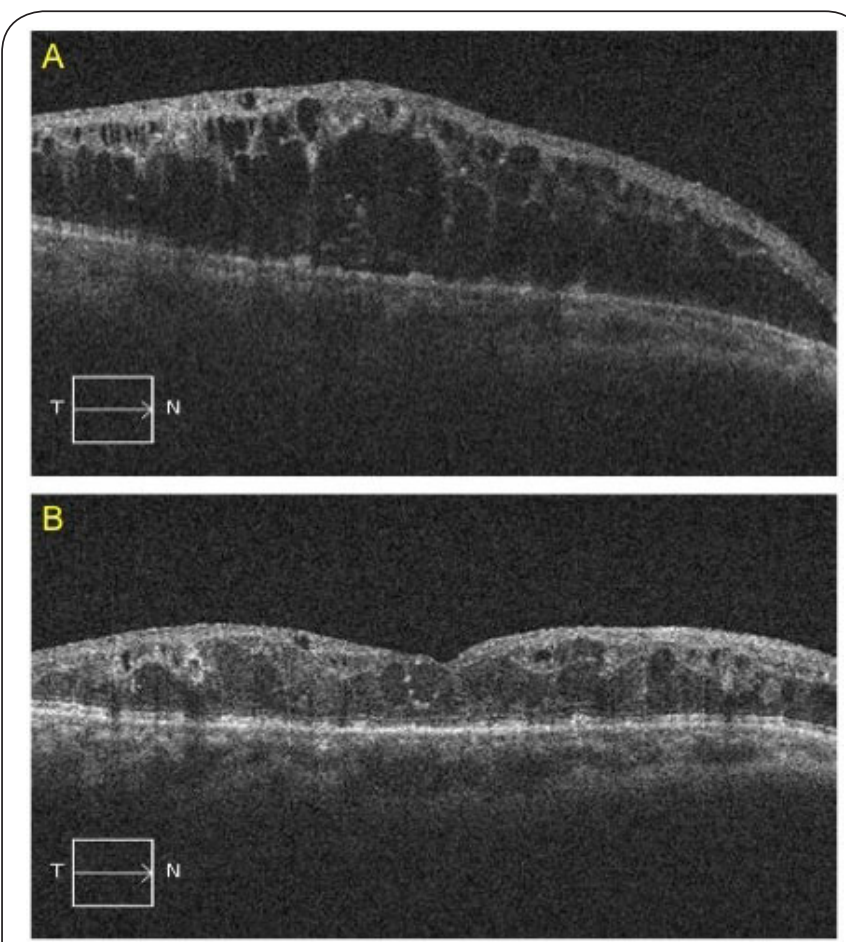

Figure 2. Macular OCT (Zeiss) images before and after intravitreal injection of ranibizumab. (A) Significant CME and small amount of subretinal fluid, BCVA 20/400, CFT 821 $\mu \mathrm{m} / 18.0 \mathrm{~mm}^{2}$ prior to treatment. (B) Significant improvement in CME, BCVA 20/80, CFT $357 \mu \mathrm{m} / 10.8 \mathrm{~mm}^{2}$ six weeks after administration of intravitreal ranibizumab.

The patient was then given a single intravitreal injection of aflibercept (2 mg). The BCVA improved to 20/50, and CFT decreased from $785 \mu \mathrm{m}$ from $319 \mu \mathrm{m}$ (Figures 3A and 3B). Subsequently, second and third intravitreal injections of aflibercept were given at monthly intervals with visual acuity stabilization at 20/50 and unchanged CFT on OCT of $320 \mu \mathrm{m}$. The intraocular pressure remained normal without evidence of neovascularization of the iris or angle. No adverse effects were noted.

\section{Discussion}

Within the last five years, multiple agents have been shown to be effective for treatment of CRVO-related macular edema, including intravitreal steroids and anti-VEGF agents (bevacizumab and ranibizumab) [10-13]. Aflibercept is a complex fusion protein composed of the second domain of human VEGF receptor 1 and the third domain of human VEGF receptor 2, linked to human IgG [14]. As such, its binding kinetics for VEGF is higher than that of bevacizumab or ranibizumab, which raises at least a theoretical possibility of improved efficacy with less frequent dosing [15]. Furthermore, aflibercept (unlike bevacizumab or ranibizumab) also binds placental growth factor (PGF), which could afford potential therapeutic benefits beyond anti-VEGF blockade.

Aflibercept is currently being evaluated in a phase 3 multicenter, 

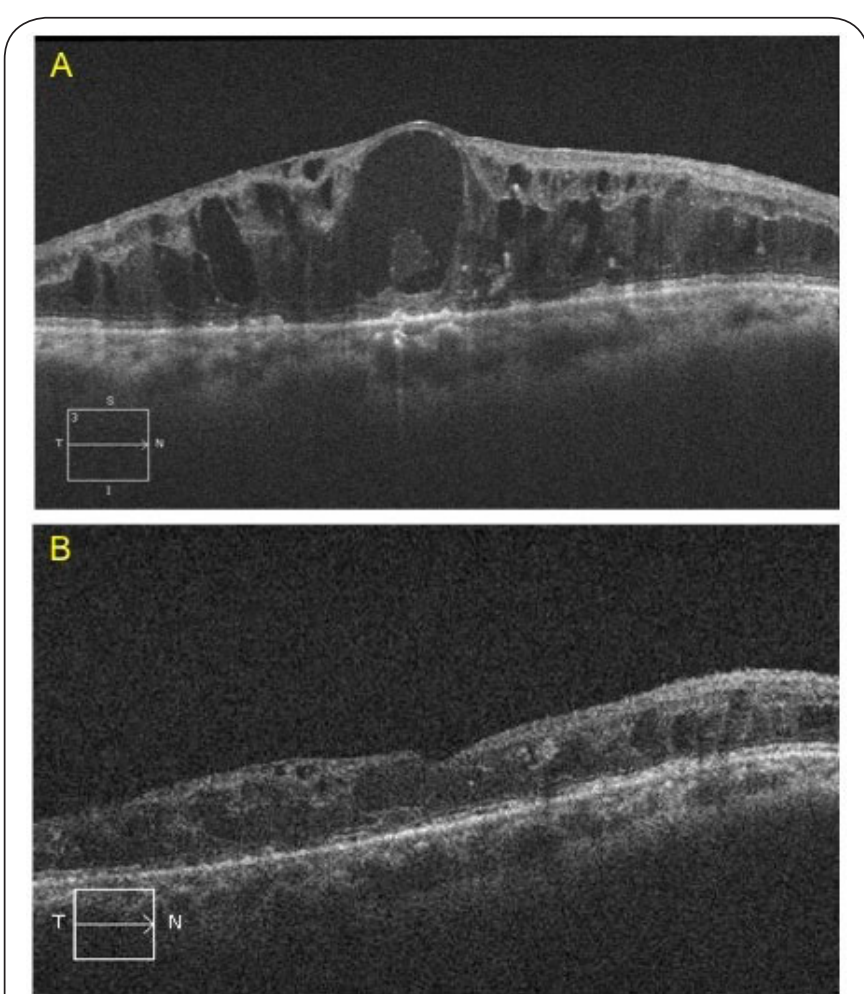

Figure 3. Macular OCT (Zeiss) images before and after intravitreal injection of aflibercept. (A) Recurrent CME with intraretinal fluid in the fovea, BCVA 20/80, CFT 785 $\mu \mathrm{m} / 14.4 \mathrm{~mm}^{2}$. (B) Clinical improvement three weeks after administration of intravitreal aflibercept with BCVA 20/50, CFT $319 \mu \mathrm{m} / 9.2 \mathrm{~mm}^{2}$.

randomized prospective trial for treatment of macular edema in CRVO (COPERNICUS), and the six month results have recently been published [9]. In this study, patients were randomized to receive either aflibercept or sham injection monthly for six months. The study included only anti-VEGF-naïve eyes, as the eyes that received prior anti-VEGF therapy in the study eye or in the fellow eye within the last three months were excluded. At 24 weeks, $56.1 \%$ of treated eyes gained 15 letters or more from baseline, versus $12.3 \%$ of sham-treated eyes, accompanied by significant improvement in CRT in eyes treated with aflibercept compared to sham [9].

Our case demonstrated a prompt visual and anatomic response to intravitreal aflibercept in an eye with $C M E$ secondary to chronic non-ischemic CRVO. Despite receiving aflibercept three years after his initial diagnosis of CRVO and after multiple injections of bevacizumab and ranibizumab, the patient presented here had an excellent clinical response to aflibercept. As such, aflibercept may be a viable treatment alternative after the administration of other anti-VEGF agents long after the initial diagnosis of CRVO. Larger head-to-head comparison studies between aflibercept and other anti-VEGF agents will determine whether aflibercept has enhanced efficacy for the treatment of CRVO.

\section{Conclusions}

Aflibercept represents an effective alternative for treatment of cystoid macular edema in CRVO patients recurrent after prior treatment with bevacizumab and ranibizumab.

\section{List of abbreviations}

CRVO: central retinal vein occlusion

VEGF: vascular endothelial growth factor

OCT: optical coherence tomography

BCVA: best corrected visual acuity

CFT: central foveal thickness

\section{Competing interests}

The authors declare that they have no competing interests.

Authors' contributions

\begin{tabular}{|l|c|c|c|c|}
\hline Authors' contributions & BT & PL & CS & SF \\
\hline Research concept and design & $\checkmark$ & $\checkmark$ & -- & $\checkmark$ \\
\hline Collection and/or assembly of data & $\checkmark$ & $\checkmark$ & $\checkmark$ & $\checkmark$ \\
\hline Data analysis and interpretation & $\checkmark$ & $\checkmark$ & -- & $\checkmark$ \\
\hline Writing the article & $\checkmark$ & $\checkmark$ & -- & $\checkmark$ \\
\hline Critical revision of the article & $\checkmark$ & -- & -- & $\checkmark$ \\
\hline Final approval of article & $\checkmark$ & -- & -- & $\checkmark$ \\
\hline
\end{tabular}

\section{Publication history}

Editor: John D. Bullock, Boonshoft School of Medicine, Wright State University, USA.

Received: 01-Apr-2014 Accepted: 11-May-2014

Published: 04-Jun-2014

\section{References}

1. Rogers SL, McIntosh RL, Lim L, Mitchell P, Cheung N, Kowalski JW, Nguyen HP, Wang JJ and Wong TY. Natural history of branch retinal vein occlusion: an evidence-based systematic review. Ophthalmology. 2010; 117:1094-1101 e5. | Article | PubMed

2. Rogers S, Mclntosh RL, Cheung N, Lim L, Wang JJ, Mitchell P, Kowalski JW, Nguyen $\mathrm{H}$ and Wong TY. The prevalence of retinal vein occlusion: pooled data from population studies from the United States, Europe, Asia, and Australia. Ophthalmology. 2010; 117:313-9 e1. | Article | PubMed Abstract I PubMed Full Text

3. Green WR, Chan CC, Hutchins GM and Terry JM. Central retinal vein occlusion: a prospective histopathologic study of 29 eyes in $\mathbf{2 8}$ cases. Retina. 1981; 1:27-55. | PubMed

4. Mclntosh RL, Rogers SL, Lim L, Cheung N, Wang JJ, Mitchell P, Kowalski JW, Nguyen HP and Wong TY. Natural history of central retinal vein occlusion: an evidence-based systematic review. Ophthalmology. 2010; 117:1113-1123 e15. | Article | PubMed

5. Natural history and clinical management of central retinal vein occlusion. The Central Vein Occlusion Study Group. Arch Ophthalmol. 1997; 115:486-91. I Article I PubMed

6. Pe'er J, Folberg R, Itin A, Gnessin H, Hemo I and Keshet E. Vascular endothelial growth factor upregulation in human central retinal vein occlusion. Ophthalmology. 1998; 105:412-6. | Article | PubMed

7. Brown DM, Campochiaro PA, Singh RP, Li Z, Gray S, Saroj N, Rundle AC, Rubio RG and Murahashi WY. Ranibizumab for macular edema following central retinal vein occlusion: six-month primary end point results of a phase III study. Ophthalmology. 2010; 117:1124-1133 e1. | Article | PubMed

8. Priglinger SG, Wolf AH, Kreutzer TC, Kook D, Hofer A, Strauss RW, Alge CS, Kunze $C$, Haritoglou $C$ and Kampik A. Intravitreal bevacizumab injections for treatment of central retinal vein occlusion: six-month results of a 
Todorich et al. Journal of Eye and Ophthalmology 2014,

http://www.hoajonline.com/journals/pdf/2055-2408-1-3.pdf

prospective trial. Retina. 2007; 27:1004-12. | Article | PubMed

9. Boyer D, Heier J, Brown DM, Clark WL, Vitti R, Berliner AJ, Groetzbach G, Zeitz O, Sandbrink R, Zhu X, Beckmann K and Haller JA. Vascular endothelial growth factor Trap-Eye for macular edema secondary to central retinal vein occlusion: six-month results of the phase 3 COPERNICUS study. Ophthalmology. 2012; 119:1024-32. | Article | PubMed

10. Ip MS, Scott IU, VanVeldhuisen PC, Oden NL, Blodi BA, Fisher M, Singerman LJ, Tolentino M, Chan CK and Gonzalez VH. A randomized trial comparing the efficacy and safety of intravitreal triamcinolone with observation to treat vision loss associated with macular edema secondary to central retinal vein occlusion: the Standard Care vs Corticosteroid for Retinal Vein Occlusion (SCORE) study report 5. Arch Ophthalmol. 2009; 127:1101-14. | Article | PubMed Abstract | PubMed Full Text

11. Haller JA, Bandello F, Belfort R, Jr., Blumenkranz MS, Gillies $M$, Heier J, Loewenstein A, Yoon YH, Jacques ML, Jiao J, Li XY and Whitcup SM. Randomized, sham-controlled trial of dexamethasone intravitreal implant in patients with macular edema due to retinal vein occlusion. Ophthalmology. 2010; 117:1134-1146 e3. | Article | PubMed

12. Hahn $P$ and Fekrat $S$. Best practices for treatment of retinal vein occlusion. Curr Opin Ophthalmol. 2012; 23:175-81. | Article | PubMed

13. Decroos FC and Fekrat $S$. The natural history of retinal vein occlusion: what do we really know? Am J Ophthalmol. 2011; 151:739-741 e2. | Article I PubMed

14. Economides AN, Carpenter LR, Rudge JS, Wong V, Koehler-Stec EM, Hartnett C, Pyles EA, Xu X, Daly TJ, Young MR, Fandl JP, Lee F, Carver S, McNay J, Bailey K, Ramakanth S, Hutabarat R, Huang TT, Radziejewski C, Yancopoulos GD and Stahl N. Cytokine traps: multi-component, highaffinity blockers of cytokine action. Nat Med. 2003; 9:47-52. | Article | PubMed

15. Heier JS, Boyer D, Nguyen QD, Marcus D, Roth DB, Yancopoulos G, Stahl N, Ingerman A, Vitti R, Berliner AJ, Yang K and Brown DM. The 1-year results of CLEAR-IT 2, a phase 2 study of vascular endothelial growth factor trap-eye dosed as-needed after 12-week fixed dosing. Ophthalmology. 2011; 118:1098-106. | Article | PubMed

\section{Citation:}

Todorich B, Lin P, Shieh C and Fekrat S. Efficacy of aflibercept for the treatment of chronic non-ischemic CRVO-associated macular edema after treatment with other anti-VEGF agents. J Eye Ophthalmol. 2014; 1:3.

http://dx.doi.org/10.7243/2055-2408-1-3 